\title{
Clinical predictive factors for radiation pneumonitis and pulmonary fibrosis during split course concurrent chemoirradiation for locally advanced non-small cell lung cancer
}

\author{
James C Marsh¹ ${ }^{* 1}$, Julie A Wendt ${ }^{2}$, Andrew Walker ${ }^{3}$, Julius V Turian ${ }^{4}$ and Krystyna Kiel ${ }^{5}$
}

\begin{abstract}
Purpose: We sought to identify factors predictive of development of radiation pneumonitis and pulmonary fibrosis following split course concurrent chemoirradiation for locally advanced non-small cell lung cancer (LA-NSCLC).

Methods and Materials: We reviewed records of 108 patients treated with regimen of split course radiotherapy (median 60 Gy in 30 fractions) and concurrent chemotherapy for stage IIla/IIlb NSCLC. Fisher's Exact Test and Paired Student T Test were performed to identify factors predictive of development of any pulmonary toxicity (pneumonitis or fibrosis of any grade) and severe pulmonary toxicity (grade 3 or higher pneumonitis, grade 2 or higher fibrosis).
\end{abstract}

Results: 56 patients (51.2\%) developed any toxicity; 22 patients (20.4\%) developed severe toxicity. The following predictive factors were identified for any and severe pulmonary toxicity, respectively: reactive airway disease (RAD), age, RV \% expected (EXP), PEF \%EXP, FEV1/FVC ratio, smoking status; and RAD, FEV1 \%EXP, FVC \%EXP, FEV1/FVC \%EXP, RV \%EXP, FEF25/75 \%EXP, PEF \%EXP, S-GAW \%, FEV1, FVC, and FEV1/FVC .

Conclusions: Our overall rates of any and severe pulmonary toxicity are acceptable. History of RAD and active smoking are protective, whereas patients with severe COPD have increased risk. A trend was seen toward improved outcomes with the use of prophylactic steroid control medication. These results should be confirmed in the context of a prospective study.

\section{Background}

Radiation therapy (RT) remains an important component of the treatment of non-small cell lung cancer (NSCLC) [1-3]. Unfortunately, the use of RT in this context is limited by toxicity to normal tissues, particular normal lung and esophagus [4-8]. Radiation-induced pulmonary damage typically manifests as radiation pneumonitis $(\mathrm{RP})$, pulmonary fibrosis $(\mathrm{PF})$, or both $[6,8]$. A number of prior studies have evaluated clinical and dosimetric predictive factors for these toxicities, with mixed results [9-14].

At our institution, patients with locally advanced NSCLC are treated either in the definitive setting to 60Gy in 30 fractions or neoadjuvant setting to $44 \mathrm{~Gy}$ in 22 fractions with a regimen of split course concurrent chemotherapy and RT. The specific details and clinical outcomes of this regimen have been previously published [15-16]. In this study, we sought to identify clinical features predictive of any pulmonary toxicity (versus none) and/or severe pulmonary toxicity (NCIC CTC Grade 3 or higher RP and/or Grade 2 or higher PF) versus none-mild toxicity using this regimen.

\section{Methods \& Materials}

After obtaining Institutional Review Board approval for this study, we identified 108 patients treated for stage IIla or IIIb (AJCC 7th

\footnotetext{
* Correspondence: jmarsh@rtsx.com

'21st Century Oncology, 9159 West Thunderbird Road, Peoria, AZ. 85381. Full list of author information is available at the end of the article
}

edition) NSCLC with an institutionally developed protocol of split course concurrent chemotherapy and RT using a split course approach. RT was delivered using standard fractionation (1.8-2 Gy once daily, 5 fractions/week), 7 or 8 fractions per cycle, 21 consecutive calendar days per cycle. The total delivered dose was typically $60 \mathrm{~Gy}$ by $2 \mathrm{~Gy}$ fractions (65 cases), with the remaining patients receiving slightly higher or lower doses due to tumor control or toxicity concerns. These patients were selected from a larger cohort of 144 patients treated with this definitive regimen at our institution; however, 36 patients received a truncated course of treatment due to toxicity, tumor progression, or a decision to proceed with surgical resection. We excluded those patients from this analysis to improve the dosimetric homogeneity of the study population.

Treatment records were reviewed to obtain toxicity data from all cases. In all cases, toxicity was graded using the $\mathrm{NCl}$ Common Toxicity Criteria Version 3 (Figure 1). We classified Grade 3 or worse RP and Grade 2 or worse PF as severe toxicity. For patients who had pulmonary function tests (PFT) performed prior to the initiation of treatment, we collected all available parameters. In cases where multiple PFTs were performed, we recorded those most immediately preceding treatment. COPD was graded using GOLD Criteria [17]. For patients administered bronchodilators during testing, an improvement in FEV1, FVC, or FEV1/FVC ratio of $12 \%$ or more or an improvement in FEF25/75 of 32\% or more was classified

(C) 2012 Marsh et al; licensee Herbert Publications Ltd. This is an open access article distributed under the terms of Creative Commons Attribution License (http://creativecommons.org/licensesby/2.0), This permits unrestricted use, distribution, and reproduction in any medium, provided the original work is properly cited 
as reversible obstructive lung disease (ROLD) [18]. Any form of documented underlying lung disease (asthma, COPD, etc.) was recorded. Patients who were taking scheduled controller medications for their underlying lung disease at the time of treatment were also identified, and the controller medication was classified as steroid-based (oral or inhaled), non-steroid based, or both (albuterol inhalers or nebulizers used as needed only were not included). Patients who initiated the use of such medications after the beginning of treatment were not included. Patients with a history of asthma or PFTs showing ROLD were classified as having reactive airway disease (RAD) [18]. We additionally noted the patients' age, the side of the primary tumor (left versus right), and the patient's smoking history. Patients were classified as never smokers, former smokers (if they quit smoking prior to the initiation of treatment), or active smokers (those who smoked during and/ or after treatment).
Dosimetric data from RT treatment plans were also reviewed for all cases. A full dosimetric analysis will be submitted in a separate manuscript. An analysis of chemotherapy-related risk factors will also be reported separately.

Fisher's Exact Test was used to compare categorical variables, and Paired Student's T Test to compare continuous variables/ means, between patients who developed any pulmonary toxicity versus no pulmonary toxicity, and between patients who developed severe pulmonary toxicity versus none to mild toxicity. $\mathrm{P}$ values .05 or less were considered statistically significant.

\section{Results}

$56 / 108$ patients (51.2\%) developed some degree of pulmonary toxicity, while 22/108 patients (20.4\%) developed severe toxicity. The following predictive factors were identified for any pulmonary toxicity versus none: history of reactive

Figure 1. $\mathrm{NCl}$ Common Toxicity Criteria Version 3 [http://ctep.cancer.gov]

\begin{tabular}{|c|c|c|c|c|c|}
\hline NAME & GRADE 1 & GRADE 2 & GRADE 3 & GRADE 4 & GRADE 5 \\
\hline ARDS & - & - & + , no intubation & + , intubated & + , death \\
\hline Aspiration & Asymptomatic & $\begin{array}{l}\text { Symptomatic, needs } \\
\text { treatment }\end{array}$ & $\begin{array}{l}\text { Pneumonia, no } \\
\text { oral intake }\end{array}$ & Life threatening & Death \\
\hline Atalectasis & Asymptomatic & Symptomatic & Operative intervention & Life threatening & Death \\
\hline Bronchospasm & Asymptomatic & $\begin{array}{l}\text { Symptomatic, no } \\
\text { effect on function }\end{array}$ & Interferes with function & Life threatening & Death \\
\hline DLco & $90-75 \%$ predicted & $50-74 \%$ predicted & $25-49 \%$ predicted & $<25 \%$ predicted & Death \\
\hline Chylothorax & Asymptomatic & $\begin{array}{l}\text { Symptomatic, needs } \\
\text { drainage }\end{array}$ & $\begin{array}{l}\text { Needs operative } \\
\text { intervention }\end{array}$ & Life threatening & Death \\
\hline Cough & $\begin{array}{l}\text { Symptomatic, no } \\
\text { narcotics needed }\end{array}$ & Narcotics needed & $\begin{array}{l}\text { Intereferes w/ } \\
\text { sleep or ADL }\end{array}$ & - & - \\
\hline Dyspnea & $\begin{array}{l}\text { DOE, can climb } 1 \\
\text { flight stairs }\end{array}$ & $\begin{array}{l}\text { DOE, can't climb } \\
1 \text { flight stairs }\end{array}$ & Interferes w/ ADL & $\begin{array}{l}\text { Dyspnea at rest, } \\
\text { needs intubation }\end{array}$ & Death \\
\hline FEV1 & $90-75 \%$ predicted & $50-74 \%$ predicted & $25-49 \%$ predicted & $<25 \%$ predicted & Death \\
\hline Fistula & $\begin{array}{l}\text { Radiographic only, } \\
\text { asymptomatic }\end{array}$ & $\begin{array}{l}\text { Symptomatic, no } \\
\text { effect on ADL }\end{array}$ & $\begin{array}{l}\text { Endoscopic or surgical } \\
\text { intervention }\end{array}$ & Life threatening & Death \\
\hline Hypoxia & - & $\begin{array}{l}\text { Decreased } \mathrm{O} 2 \text { sats } \\
\text { w/ exertion }\end{array}$ & $\begin{array}{l}\text { Decreased } \mathrm{O} 2 \text { sats } \\
\text { at rest, needs } \mathrm{O} 2\end{array}$ & $\begin{array}{l}\text { Life threatening, } \\
\text { intubation needed }\end{array}$ & Death \\
\hline $\begin{array}{l}\text { Airway stenosis } \\
\text { or obstruction }\end{array}$ & $\begin{array}{l}\text { Radiographic only, } \\
\text { asymptomatic }\end{array}$ & $\begin{array}{l}\text { Symptomatic, medical } \\
\text { treatment }\end{array}$ & $\begin{array}{l}\text { Stridor, needs } \\
\text { endoscopic treatment }\end{array}$ & $\begin{array}{l}\text { Life threatening, } \\
\text { needs tracheostomy }\end{array}$ & Death \\
\hline Pneumonitis & $\begin{array}{l}\text { Asymptomatic, } \\
\text { radiographic only }\end{array}$ & $\begin{array}{l}\text { Symptomatic, but } \\
\text { no effect on ADL }\end{array}$ & $\begin{array}{l}\text { Interferes } \mathrm{w} / \mathrm{ADL} \text {, } \\
\mathrm{O} 2 \text { required }\end{array}$ & $\begin{array}{l}\text { Life threatening, } \\
\text { intubation needed }\end{array}$ & Death \\
\hline Pleural effusion & Asymptomatic & $\begin{array}{l}\text { Up to } 2 \text { thoracenteses } \\
\text { or diuretic }\end{array}$ & $\begin{array}{l}\text { Tube drainage, } \mathrm{O} 2 \\
\text { needed, pleurodesis, } \\
.2 \text { thoracenteses }\end{array}$ & Life threatening & Death \\
\hline Pneumothorax & $\begin{array}{l}\text { Asymptomatic, } \\
\text { radiographic only }\end{array}$ & Intervention required & $\begin{array}{l}\text { Surgery or sclerosis } \\
\text { needed }\end{array}$ & Life threatening & Death \\
\hline Pulmonary fibrosis & $<25 \%$ of lung affected & $25-49 \%$ of lung affected & $50-74 \%$ of lung affected & $\begin{array}{l}75 \%+\text { of lung } \\
\text { affected }\end{array}$ & Death \\
\hline Vital capacity & $75-90 \%$ predicted & $50-74 \%$ predicted & $25-49 \%$ predicted & $<25 \%$ predicted & Death \\
\hline Other & Mild & Moderate & Severe & Life threatening & Death \\
\hline
\end{tabular}

Note: Other/operative and upper airway toxicities not included in this table but available at above site 
airway disease (RAD), age, high or intermediate risk dosimetry, RV \% expected (EXP), PEF \%EXP, FEV1/FVC ratio, and smoking status. For severe pulmonary toxicity the following factors were predictive: RAD, FEV1 \%EXP, FVC \%EXP, FEV1/FVC \%EXP, RV \%EXP, FEF25/75 \%EXP, PEF \%EXP, S-GAW \%, FEV1, FVC, and FEV1/FVC.

A history of RAD was found to be protective against any toxicity ( $p .04)$ and severe toxicity ( $p .03)$. When a history of RAD was compared to a history of COPD, RAD was found to be borderline significant in terms of protection against any toxicity ( $p$.08) and statistically significant for protecting against severe toxicity ( $p .03$ ). A history of any COPD was not predictive of any or severe toxicity ( .27 and .90 , respectively), nor was it predictive after stratification by Goldman Criteria (severe, moderate, mild) although moderate to severe disease did approach significance when compared with none to mild disease for any toxicity ( $p .06)$.

Interesting, we saw a higher rate of any toxicity for patients $<65$ years of age ( $p .05$ ), although the difference did not reach statistical significance for severe toxicity $(p$.67). Most of this difference was a higher rate of grade 1 pneumonitis or fibrosis in the younger patients. No difference was seen between smokers and non-smokers for either any or severe toxicity, but current smokers had a lower rate of any toxicity than former smokers( $p$ .05), while no difference was seen between current smokers and nonsmokers or between former smokers and non-smokers.

Steroid controllers did reduce the rate of any toxicity compared to no controller medication (30\% versus $54 \%$ ), but this difference did not reach statistical significance ( $p$.13), likely due to the small number of patients who took steroid controller medication during their treatment. There was clearly no difference in rates of severe toxicity (19\% versus $20 \%, p .70$ ).

\begin{tabular}{lccc}
\hline & $\begin{array}{c}\text { Any Pneu- } \\
\text { monitis/ } \\
\text { fibrosis }\end{array}$ & $\begin{array}{c}\text { No Pneu- } \\
\text { monitis/ } \\
\text { fibrosis }\end{array}$ & P \\
\hline RAD (30 pts) & 11 & 19 & 0.04 \\
No RAD (78 pts) & 45 & 33 & - \\
<65 (47 pts) & 29 & 18 & 0.05 \\
>65 (61 pts) & 27 & 34 & - \\
RV \%EXP & 132.11 & 162.87 & 0.02 \\
PEF \%EXP & 76.23 & 61.74 & 0.04 \\
FEV1/FVC & 0.72 & 0.64 & 0.01 \\
CURRENT SMOKING (43 pts) & 20 & 23 & 0.05 \\
FORMER SMOKING (57 pts) & 36 & 19 & - \\
\hline
\end{tabular}

Table I. Clinical outcomes: any toxicity versus none

RAD: reactive airway disease

COPD: chronic obstructive pulmonary disease
The use of non-steroid controller did not affect rates of any or severe toxicity when compared with no controller ( $p .44$ and .90 , respectively) or steroid controller (p.36 and .46, respectively).

Tumor location (right versus left) did not predict for any or severe toxicity, although there was a trend toward higher rates of any toxicity for left sided tumors ( $p$.08). These data are shown in Tables I and II.

\section{Discussion}

While esophagitis and fatigue are the most commonly reported acute toxicities in the treatment of thoracic malignancies, the most common and rate-limiting subacute and late toxicity remains pulmonary [6,8-9,11,13-14]. Prior studies have identified a number of clinical and dosimetric factors which are predictive for the development of subsequent RP and PF [9-14,19-21]. The results of these studies have been mixed and sometimes contradictory, with some implicating dosimetric factors such as

\begin{tabular}{llll}
\hline & $\begin{array}{l}\text { Severe } \\
\text { Pneumoni- } \\
\text { tis/Fibrosis }\end{array}$ & $\begin{array}{l}\text { No Severe } \\
\text { Pneumoni- } \\
\text { tis/Fibrosis }\end{array}$ & p \\
\hline RAD (29 pts) & 2 & 27 & 0.03 \\
No RAD (79 pts) & 20 & 59 & - \\
RAD (29 pts) & 2 & 27 & 0.05 \\
COPD (30 pts) & 8 & 22 & - \\
FEV1 \%EXP & 79.72 & 68.34 & 0.01 \\
FVC \%EXP & 86.8 & 78.71 & 0.04 \\
FEV1/FVC \%EXP & 94.08 & 85.73 & 0.02 \\
RV \%EXP & 125.49 & 148.62 & 0.01 \\
FEF25/75 \%EXP & 54.86 & 42.43 & 0.02 \\
PEF \%EXP & 80.22 & 68 & 0.01 \\
S-GAW \% & 95.16 & 73.35 & 0.03 \\
FEV1 & 2.08 & 1.88 & 0.01 \\
FVC & 2.88 & 2.76 & 0.05 \\
FEV1/FVC & 0.72 & 0.68 & 0.003 \\
PEF & 5.42 & 4.85 & 0.03 \\
\hline
\end{tabular}

Table II. Clinical outcomes: severe toxicity versus none to moderate

RAD: reactive airway disease

COPD: chronic obstructive pulmonary disease 
various Vdose or mean lung dose (ipsilateral or bilateral) and others implicating clinical factors such as smoking status, a history of COPD, age, tumor location, and various PFT metrics [9-14,19-22]. We are unaware of any prior studies that have evaluated the relationship between a history of asthma/RAD and the risk of subsequent RP or PF. Prior studies have also shown conflicting results with regard to the prophylactic use of steroids (oral or inhaled) as a preventive measure against the development of RP or PF [13-14,23].

A recent growing body of evidence implicates the central role of TGF beta and other cytokines in the development of RP and PF [24-30]. Unfortunately, this testing is not routinely available at our institution, and thus we cannot correlate baseline or subsequent cytokine levels with the development of RP or PF in our series. It is interesting to note that in our study both a history of RAD and current smoking status (defined as active smoking during treatment with or without continued smoking after treatment) were found to be protective against the development of RP and PF, because both conditions are known to be associated with elevated basal circulating TGF beta levels [31-33]. Also, both conditions are known to favor a $\mathrm{TH} 2$ immunologic response to noxious stimuli, while the dominant pathway leading to upregulation of TGF beta involves a TH1 response [34-39]. While a history of RAD has not specifically been evaluated as a predictive factor for RP or PF in prior studies, the influence of cigarette smoking on the development of RP and PF has shown conflicting results in prior studies, with some showing an increase in risk, others no relationship, and still others a protective effect [12, 40-42] These differences in outcome may reflect differences in the definition of current versus former smoking status utilized in these prior studies [40-42]. It is tempting to speculate that the upregulation of $\mathrm{TH} 2$ responses in the lungs of active smokers and patients with RAD may be preventing or ameliorating increases in TGF beta during treatment and thereby protecting against the development of subsequent toxicity, but this relationship cannot be proven in this study as we do not have TGF beta levels available for review.

We did not find a significant relationship between a history of COPD and the subsequent development of RP or PF for all patients, but we did find a correlation between moderate to severe disease as defined by the GOLD Criteria and the development of toxicity [18]. Prior studies have shown mixed results as regards this correlation, and these differences may be explained by differences in the definition of COPD (prior clinical diagnosis versus assessment of PFT data) and whether disease severity was specified as in this study $[9,13,19,21]$. We did find very strong correlations between a number of PFT metrics and the risk of developing toxicity, and these metrics including measures of spirometry (absolute and/or percent expected FVC, FEV1, FEV1/FVC ratio, PEF, and FEF 25/75), lung volumes (absolute and/or percent expected TLC, RV, and ERV), measures of resistance (GAW), and respiratory muscle force (VC MAX). Thus, it may be the actual degree of lung dysfunction rather than a definition of COPD per se which predicts for risk, and this influence may be ameliorated in the setting of RAD/ reversible obstructive disease either because of differences in inflammatory response as described above or increased lung plasticity in the setting of reversible obstructive disease [18].

We found that patients 65 years of age or younger had higher rates of toxicity than older patients, whereas prior studies have shown either an increased risk with increasing age or no relationship [9,13-14]. Since these patients were not treated in the setting of a prospective clinical trial, it is possible that this finding is the result of treatment bias. It is also possible that this unexpected finding is related to our institutional treatment approach of split course therapy, since we have noted in previous publications that our approach is much better tolerated by elderly patients and those with significant medical comorbidities than standard protocols[15-16]. It is possible that older patients are less able to mount a robust TH1 response to noxious stimuli and that this might lead to lower TGF beta and other cytokine levels during and after therapy, resulting in lower rates of subsequent toxicity, but this hypothesis has not been proven, and our lack of TGF beta levels precludes an assessment in this study [42].

Tumor location has been shown to be predictive of toxicity in some but not all prior studies, with some showing no relationship (for left versus right, or for individual lobes) and others showing increased toxicity with right-sided or lower lobe tumors $[22,43]$. We found a borderline statistically significant increase in toxicity for left-sided tumors, but there was no difference in severe toxicity based on tumor location.

It is possible that the introduction of planned radiotherapy treatment breaks in our regimen may influence our patterns of toxicity. As noted in our prior publications, our regimen has an overall favorable toxicity profile, but most of the reduction in toxicity probably relates to reductions in acute hematologic toxicity and esophagitis (resulting in very little weight loss during treatment and few unplanned treatment breaks)[1516]. Since neither RP nor PF represent early toxicity events, it is unlikely that the increase in overall radiation therapy treatment time (from approximately 6-7 weeks with a traditional approach to 12 weeks with our approach) would meaningfully influence the rate of these toxicities [44]. Therefore, we feel that the risks of our analysis can likely be generalized to patients treated with more traditional regimens.

The strengths of the current study are the homogeneity of the study population and the treatment regimen. The weaknesses our study include its retrospective nature, the fact that the patients being reviewed were not treated in the context of a clinical trial (introducing the possibility of selection bias and potential inhomogeneity in radiotherapy plan review and approval), and the lack of TGFbeta/ cytokine data. As mentioned previously, we will be reporting the results of our dosimetric analysis separately, and we will also be performing a separate analysis of the various chemotherapy regimen employed in this series. 


\section{Conclusion}

Following treatment of locally advanced NSCLC with our institutional protocol of split course concurrent chemoirradiation, we found that asthma/RAD and smoking during and /or after definitive treatment reduced rates of toxicity, while a history of moderate to severe COPD (by GOLD criteria) increased the risk of toxicity. We also found that multiple baseline measures of pulmonary function were predictive of toxicity, and that the use of steroid controller trended toward lower rates of toxicity. These findings should be further validated in the context of a prospective trial.

\author{
Author details \\ ${ }^{2}$ Allergy, Asthma, \& Immunology Associates, LTD, Scottsdale, AZ. \\ ${ }^{3}$ Rush Medical College, Chicago, IL. 4 Department of Radiation \\ Oncology, Rush University Medical Center, Chicago, IL. \\ ${ }^{5}$ Department of Radiation Oncology, Rush \\ University Medical Center, Chicago, IL.
}

\section{Article History}

Editor: Xingming Deng, Emory University School of Medicine United States of America.

EIC: G.J. Peters, VU University Medical Center, Netherlands. Received: 29-Dec-2011 Accepted: 31-Jan-2012

Published: 20-Mar-2012

\section{References}

1. Gopal, R. S. et al. ACR Appropriateness Criteria(R) on Induction and Adjuvant Therapy for Stage N2 Non-Small-Cell Lung Cancer: expert panel on radiation oncology-lung. Int J Radiat Oncol Biol Phys 78, 969-974.

2. Gewanter, R. M. et al. ACR Appropriateness Criteria: nonsurgical treatment for non-small-cell lung cancer: good performance status/definitive intent. Curr Probl Cancer 34, 228-249.

3. Rosenzweig, K. E. et al. ACR appropriateness criteria on nonsurgical treatment for non-small-cell lung cancer: poor performance status or palliative intent. J Am Coll Radiol 6, 85-95.

4. De Ruysscher, D. et al. European Organisation for Research and Treatment of Cancer recommendations for planning and delivery of high-dose, high-precision radiotherapy for lung cancer. J Clin Oncol 28, 5301-5310.

5. Senan, S. et al. Literature-based recommendations for treatment planning and execution in high-dose radiotherapy for lung cancer. Radiother Oncol 71, 139-146.

6. Graves, P. R. et al. Radiation pulmonary toxicity: from mechanisms to management. Semin Radiat Oncol 20, 201-207.

7. Rose, J. et al. Systematic review of dose-volume parameters in the prediction of esophagitis in thoracic radiotherapy. Radiother Oncol 91, 282-287.

8. Milano, M. T. et al. Normal tissue tolerance dose metrics for radiation therapy of major organs. Semin Radiat Oncol 17, 131-140.
9. Shi, A. et al. Analysis of clinical and dosimetric factors associated with severe acute radiation pneumonitis in patients with locally advanced non-small cell lung cancer treated with concurrent chemotherapy and intensitymodulated radiotherapy. Radiat Oncol 5, 35.

10. Bentzen, S. M. et al. Biomarkers and surrogate endpoints for normal-tissue effects of radiation therapy: the importance of dose-volume effects. Int J Radiat Oncol Biol Phys 76, S145-150.

11. Rodrigues, G. et al. Prediction of radiation pneumonitis by dose - volume histogram parameters in lung cancer--a systematic review. Radiother Oncol 71, 127-138.

12. Johansson, S. et al. Effects of ongoing smoking on the development of radiation-induced pneumonitis in breast cancer and oesophagus cancer patients. Radiother Oncol 49, 41-47.

13. Mehta, V. Radiation pneumonitis and pulmonary fibrosis in non-small-cell lung cancer: pulmonary function, prediction, and prevention. Int J Radiat Oncol Biol Phys 63, 5-24.

14. Mazeron, R. et al. Predictive factors of late radiation fibrosis: a prospective study in nonsmall cell lung cancer. Int J Radiat Oncol Biol Phys 77, 38-43.

15. Gielda, B. T. et al. Split-course chemoradiotherapy for locally advanced non-small cell lung cancer: a single-institution experience of 144 patients. $J$ Thorac Oncol 6, 1079-1086.

16. Gielda, B. T. et al. Weight gain in advanced nonsmall-cell lung cancer patients during treatment with split-course concurrent chemoradiotherapy is associated with superior survival. Int $\mathrm{J}$ Radiat Oncol Biol Phys 81, 985-991.

17. Fromer, L. et al. A review of the GOLD guidelines for the diagnosis and treatment of patients with COPD. Int J Clin Pract 62, 1219-1236.

18. British Thoracic Society Scottish Intercollegaite Guidelines Network. British guidelines on the management of asthma. Thorax 2008; Suppl 4:iv1121.

19. Barriger, R. B. et al. Dose-volume analysis of radiation pneumonitis in non-small-cell lung cancer patients treated with concurrent cisplatinum and etoposide with or without consolidation docetaxel. Int J Radiat Oncol Biol Phys 78, 1381-1386.

20. Oh, D. et al. Prediction of radiation pneumonitis following high-dose thoracic radiation therapy by $3 \mathrm{~Gy} /$ fraction for non-small cell lung cancer: analysis of clinical and dosimetric factors. Jpn J Clin Oncol 39, 151-157.

21. Rancati, $\mathrm{T}$. et al. Factors predicting radiation pneumonitis in lung cancer patients: a retrospective study. Radiother Oncol 67, 275-283.

22. Yamada, M. et al. Risk factors of pneumonitis following chemoradiotherapy for lung cancer. Eur J Cancer 34, 71-75.

23. Pagel, ]. et al. [The inhalation versus systemic prevention of pneumonitis during thoracic irradiation]. Strahlenther Onkol 174, 25-29.

24. Fleckenstein, K. et al. Using biological markers to predict risk of radiation injury. Semin Radiat Oncol 17, 89-98. 
25. Zhao, L. et al. Elevation of plasma TGF-beta 1 during radiation therapy predicts radiationinduced lung toxicity in patients with non-smallcell lung cancer: a combined analysis from Beijing and Michigan. Int J Radiat Oncol Biol Phys 74, 1385-1390.

26. Kim, J. Y. et al. The TGF-beta 1 dynamics during radiation therapy and its correlation to symptomatic radiation pneumonitis in lung cancer patients. Radiat Oncol 4, 59.

27. Anscher, M. S. et al. Risk of long-term complications after TFG-beta1-guided very-highdose thoracic radiotherapy. Int J Radiat Oncol Biol Phys 56, 988-995.

28. Chen, Y. et al. Radiation pneumonitis and early circulatory cytokine markers. Semin Radiat Oncol 12, 26-33.

29. Arpin, D. et al. Early variations of circulating interleukin-6 and interleukin-10 levels during thoracic radiotherapy are predictive for radiation pneumonitis. J Clin Oncol 23, 8748-8756.

30. Hart, J. P. et al. Cytokine profiling for prediction of symptomatic radiation-induced lung injury. Int $J$ Radiat Oncol Biol Phys 63, 1448-1454.

31. Halwani, R. et al. Role of transforming growth factor-beta in airway remodeling in asthma. Am J Respir Cell Mol Biol 44, 127-133.

32. Makinde, T. et al. The regulatory role of TGF-beta in airway remodeling in asthma. Immunol Cell Biol 85, 348-356.

33. Adcock, I. M. et al. Chronic obstructive pulmonary disease and lung cancer: new molecular insights. Respiration 81, 265-284.

34. Sumi $Y$, Hamid $Q$, Airway remodeling in asthma. Allergol Int 56, 341-348.

35. Nizri, E. et al. Activation of the cholinergic antiinflammatory system by nicotine attenuates neuroinflammation via suppression of Th1 and Th17 responses. J Immunol 183, 6681-6688.

36. Lloyd CM, Hessel EM, Functions of T cells in asthma: more than just $\mathbf{T}(\mathbf{H}) 2$ cells. Nat Rev Immunol 10, 838-848.

37. Kaiko, G. E. et al. Immunological decision-making: how does the immune system decide to mount a helper T-cell response? Immunology 123, 326-338.

38. Noma, T. [Helper T cell paradigm: Th17 and regulatory $T$ cells involved in autoimmune inflammatory disorders, pathogen defense and allergic diseases]. Nihon Rinsho Meneki Gakkai Kaishi 33, 262-271.

39. Franzen, L. et al. Does smoking protect against radiation-induced pneumonitis? Int J Radiat Biol 56, 721-724.

40. Jin, H. et al. Dose-volume thresholds and smoking status for the risk of treatment-related pneumonitis in inoperable non-small cell lung cancer treated with definitive radiotherapy. Radiother Oncol 91, 427-432.

41. Nieder, C. et al. Effects of smoking cessation on hypoxia and its potential impact on radiation treatment effects in lung cancer patients. Strahlenther Onkol 184, 605-609.

42. Shurin MR, et al. Aging and the dendritic cell cystem: implications for cancer. Crit Rev Oncol Hematol 64, 90-105.
43. Vinogradskiy $Y$, et al. Investigation of the relationship between gross tumor volume location and pneumonitis rates using a large clinical database of non-small cell lung cancer. Int J Radiat Oncol Biol Phys [Epub ahead of print]

44. Hall EJ, Giaccia AJ, Ch.19 Clinical responses of normal tissues, from Radiobiology for the Radiologist, Sixth Edition. Lippincott, Williams, \& Wilkins 2006. 